\title{
Long-term follow-up study of loose combined cutting seton surgery for patients with high anal fistula
}

\author{
Congcong Zhi ${ }^{1}$, Zichen Huang ${ }^{2}$, Dun Liu ${ }^{2}$, Lihua Zheng ${ }^{1}$ \\ ${ }^{1}$ Proctology Department, China-Japan Hospital, Beijing, China; ${ }^{2}$ Graduate School of Beijing University of Chinese Medicine (Master and Doctoral \\ Class of 2020 in China-Japan Friendship Hospital), Beijing, China \\ Contributions: (I) Conception and design: L Zheng, C Zhi; (II) Administrative support: Z Huang; (III) Provision of study materials or patients: L \\ Zheng, C Zhi; (IV) Collection and assembly of data: C Zhi, L Zheng, D Liu; (V) Data analysis and interpretation: C Zhi, Z Huang, L Zheng; (VI) \\ Manuscript writing: All authors; (VII) Final approval of manuscript: All authors. \\ Correspondence to: Prof. Lihua Zheng, PhD. Proctology Department, China-Japan Hospital, Beijing 100029, China. Email: btv126@126.com.
}

\begin{abstract}
Background: The treatment of high anal fistula (HAF) is still difficult for clinical surgeons. Our previous study demonstrated the short-term benefit of loose combined cutting seton (LCCS) for patients with HAF. This study aimed to evaluate the long-term effectiveness of LCCS for treating HAF patients.

Methods: We retrospectively enrolled consecutive HAF patients who received LCCS therapy in our hospital between March 2014 and July 2017. After enrollment, all patients were followed up by clinical review. The patients' clinical information and most recent follow-up results were collected. Pain was assessed by the visual analog scale (VAS), and the severity of fecal incontinence was assessed by the Wexner Continence Grading Scale. We also assessed the patients' quality of life (QOL) using a the MOS item short from health survey (SF-36) questionnaire. HAF healing was considered the primary outcome, while the fistula recurrence rate, severity of fecal incontinence, and QOL were the secondary outcomes.

Results: In total, 22 patients (18 male, four female) were enrolled in the final analysis. The mean duration of follow-up was 3.65 years (interquartile range: 3.55-4.22; range, 3.50-5.43). All patients were cured and there was no recurrence during the follow-up period. Eight patients reported a Wexner score of 1, while the remaining patients reported a score of 0 at the final follow-up. Furthermore, one patient had a VAS score of 1 , while the remaining patients had a VAS score of 0 , which indicated almost no postoperative pain. The QOL of all patients improved significantly.
\end{abstract}

Conclusions: LCCS is an effective method to treat HAF patients. Large, multicenter randomized controlled trials are warranted.

Keywords: High anal fistula (HAF); cutting seton; loose seton; continence; long-term follow-up

Submitted May 17, 2021. Accepted for publication Jul 14, 2021.

doi: $10.21037 / \mathrm{atm}-21-3242$

View this article at: https://dx.doi.org/10.21037/atm-21-3242

\section{Introduction}

Anal fistula (AF) is a common clinical disease, especially in young men. Statistically, AF accounts for approximately $8 \%$ of the population in Western countries and 3.6\% in China (1-3). High anal fistula (HAF) refers to an anorectal fistula with multiple external orifices and multiple channels with the internal opening passing through the deep layer of the external sphincter. Hence, the upper $2 / 3$ of the external sphincter is affected by HAF. Due to the special anatomical structure of the human body, treatment of this type of AF is difficult and has a high recurrence rate $(4,5)$. If improperly handled, HAF will affect the physiological functions of the surrounding organs and seriously affect the health and the quality of life (QOL) of patients. The main treatment target for HAF patients focuses on healing of the fistula lesion, prevention of recurrence, and improvement of patients' bowel habits $(5,6)$. In clinical practice, several methods have 
been introduced for the treatment of HAF, including fibrin sealant, fistula plug, ligation of intersphincteric fistula tract (LIFT), endorectal or dermal advancement flap, videoassisted anal fistula treatment, and traditional Chinese medicine (TCM) (7-11). However, the rate of healing after treatment remains extremely low $(8,12)$.

Seton techniques have been shown to be effective for HAF, with a high cure rate and a low rate of incontinence. Significant progress has been made in the materials and techniques used in seton-base treatment $(13,14)$. The recurrence rates of seton-base treatment range from $8 \%$ to $22 \%$. However, seton techniques are mainly based on the experience of the surgeon (15-17). The loose seton technique can improve drainage and accelerates the process of healing, without increasing the risk of injury to the sphincter (13). However, in some patients, the odds of fibrosis resulting in treatment failure increase when using this technique. Although the cutting seton can completely cure fistula by gradually transecting the external sphincter muscle, it often results in some complications, including incontinence and even severe pain (18).

In order to efficiently assist patients with HAF and improve their QOL, the development of treatment methods with high rates of healing and low rates of recurrence, incontinence, and pain is warranted. Our previous retrospective study showed that loose combined cutting seton (LCCS) was effective for HAF patients, with high cure rate, low rate of incontinence, and less pain (19). In this study, we aim to observe the long-term effectiveness of LCCS in these patients. We present the following article in accordance with the STROBE reporting checklist (available at https://dx.doi.org/10.21037/atm-21-3242).

\section{Methods}

\section{Study design and patients}

We enrolled consecutive patients with HAF who received LCCS therapy in our hospital between March 2014 and July 2017 according to the inclusion and exclusion criteria. The definition of HAF was described previously (19). Briefly, HAF refers to the fistula and its branches passing over the levator ani muscle and the anorectal ring. The inclusion criteria were as follows: (I) patients aged at least 18 years; (II) those with clearly diagnosed HAF; and (III) patients undergoing their first treatment for HAF. The exclusion criteria were as follows: (I) those with inflammatory bowel disease (IBD) or trauma-induced fistula; (II) patients who could not tolerate the operation due to their physical condition; (III) those with a life expectancy of less than 3 months; (IV) patients with cancers, severe malnutrition, severe heart or lung diseases, liver cirrhosis, or renal failure; and (V) pregnant or lactating women. This was a retrospective study involving enrolled patients, and their baseline characteristics and follow-up information was recorded and analyzed. This study was conducted in accordance with the principles of the Declaration of Helsinki (as revised in 2013), and was approved by the ethics committee of the China-Japan Friendship Hospital (approval license No.: 2019-SFZX-7). Written informed consent was obtained from every patient who was eventually enrolled in this study.

\section{Treatment procedures}

Treatment procedures were described in detail in our previous study and all operations were conducted by the same team of surgeons led by Dr. Zheng (19).

\section{Data collection and outcome measures}

The patients' baseline characteristics were collected from hospital records, which included general demographics information, disease history, co-morbidities, details of clinical manifestation of the fistula, fistula surgical procedure, and medication. Preoperatively, all patients underwent blood cell counting, liver and renal function tests, and fast glucose and serum lipid levels tests. Additionally, some patients received endoanal ultrasonography and anorectal pressure (AP) manometry to identify the location of the internal orifice and the morphological features of the fistula. All patients were followed up by clinical review at 1, 3, 6 months, and then annually after LCCS surgery. In this study, we conducted an additional follow-up for all patients to collect information of their most recent status. At the follow-up interviews, all patients were asked to visit the outpatient clinic in person to receive a repeated physical examination (including anal inspection and digital anal examination), endoanal ultrasonography, and anorectal manometry, especially at the most recent follow-up. Moreover, if a patient suffered from unbearable discomfort or suspected recurrence, they were asked to visit a clinic at any time.

The criteria of healing were as follows: (I) incision heals without secretions; and (II) endoanal ultrasonography reveals no fistula image. As for recurrence of the fistula, 
Table 1 Baseline characteristics (19)

\begin{tabular}{|c|c|}
\hline Characteristics & Outcome \\
\hline Age, years* & $36.1(30.5-50.5)$ \\
\hline Male, n (\%) & $18(81.8)$ \\
\hline BMI $\left(\mathrm{kg} / \mathrm{m}^{2}\right)^{\#}$ & $24.4 \pm 1.3$ \\
\hline Hypertension, n (\%) & $1(4.5)$ \\
\hline \multicolumn{2}{|l|}{ Clinical presentation, n (\%) } \\
\hline Perianal mass & $16(72.7)$ \\
\hline Perianal pain & $19(86.4)$ \\
\hline Anal secretion & $13(59.1)$ \\
\hline Fever & $4(18.2)$ \\
\hline Anal pendant expansion & $5(22.7)$ \\
\hline Duration of HAF (months) ${ }^{*}$ & $12(2,36)$ \\
\hline No. of external orifice of fistula & $1(0-2)$ \\
\hline No. of fistula tracts ${ }^{\wedge}$ & $1(1-2)$ \\
\hline \multicolumn{2}{|l|}{ Shape of fistula, n (\%) } \\
\hline Homotopic line & $3(15.0)$ \\
\hline Full horseshoe & $6(30.0)$ \\
\hline Semi-horseshoe & $11(55.0)$ \\
\hline \multicolumn{2}{|l|}{ Position of internal orifice, $\mathrm{n}(\%)$} \\
\hline 1 o'clock & $1(4.5)$ \\
\hline 6 o'clock & $19(86.4)$ \\
\hline 7 o'clock & $1(4.5)$ \\
\hline
\end{tabular}

*, median with IQR; *, mean $\pm \mathrm{SD}$; ', median with range; HAF, high anal fistula; BMI, body mass index. The present research is continuous with a previous study published before. So, this table is derived from that article (19).

the incision does not heal 3 months after surgery, the tissue around the incision still produces secretions 3 months after surgery, fistula is suggested again by endoanal ultrasonography, and repeated surgery is considered necessary for the original lesions.

The visual analog scale (VAS) was used to evaluate lesion-associated pain. VAS scores range from 0 (no pain) to 10 (extremely severe pain). The Wexner Continence Grading Scale (WCGS) was used to assess the severity of fecal incontinence. It has five domains (solid, liquid, gas, pad wearing, and lifestyle alterations), with each domain scored from 0 (no incontinence) to 4 (severe incontinence).

The quality of life (QOL) of each patient was assessed by the MOS item short from health survey (SF-36) questionnaire. Due to the limited impact on QOL and the nature of anal fistula, we only requested patients to answer six questions (question I-IV) relating to the following aspects: (I) general health; (II) limitations of activities; (III) physical health problems; (IV) emotional health problems; (V) social activities; and (VI) pain. These questions could effectively reflect the impact of treatment for anal fistula on QOL. The question "Compared to 1 year ago, how would you rate your health in general now?" in the "general health" domain was revised to "Compared to the status before surgery, how would you rate your health in general now?".

The primary outcome in the present study was HAF cure. Secondary outcomes included the recurrence of HAF, fecal incontinence, and QOL.

\section{Statistical analysis}

The Statistical Program for Social Sciences (SPSS) version 22.0 for Windows (IBM, Chicago, USA) was used for data processing. Descriptive statistics were applied to summarize the baseline characteristics of enrolled patients. Continuous data were expressed as medians with interquartile ranges (IQRs), while categorical variables were expressed as numbers (percentages). A $\mathrm{P}$ value $<0.05$ was considered statistically significant.

\section{Results}

\section{Baseline characteristics}

Twenty-two patients with HAF were included in the final analysis, including 19 males (86.4\%) and three (13.6\%) females. At the most recent follow-up, these patients had a median age of 44.0 years, and an average body mass index (BMI) of $(24.4 \pm 1.3) \mathrm{kg} / \mathrm{m}^{2}$. Four patients $(18.2 \%)$ had or developed hypertension during follow-up. None of the remaining patients had any comorbidities. The details of the patients' baseline characteristics before LCCS treatment are shown in Table 1.

These patients had a median HAF duration of 12 months (IQR: 2-36 months). Clinical presentation at baseline in these patients included perianal pain $(\mathrm{n}=19,86.4 \%)$, perianal mass $(\mathrm{n}=16,72.7 \%)$, anal secretion $(\mathrm{n}=13,59.1 \%)$, anal pendent expansion $(n=5,22.7 \%)$, and fever $(n=4,18.2 \%)$. Most patients had only one fistula tract with only one external opening. The internal opening was in the 6 o'clock position in $18(81.8 \%)$ patients and the 7 o'clock position in 
Table 2 Results of anorectal manometry in 11 patients at the most recent follow-up

\begin{tabular}{lc}
\hline Variables & Value \\
\hline Anal resting pressure $(\mathrm{mmHg}$, mean $\pm \mathrm{SD})$ & $76.9 \pm 8.9$ \\
$\begin{array}{l}\text { Maximum systolic pressure } \\
\text { (mmHg, mean } \pm \mathrm{SD})\end{array}$ & $139.8 \pm 20.7$ \\
$\begin{array}{l}\text { Rectal anal pressure difference } \\
\text { (mmHg, mean } \pm \mathrm{SD})\end{array}$ & $62.9 \pm 24.7$ \\
High pressure zone $(\mathrm{cm}$, mean $\pm \mathrm{SD})$ & $4.0 \pm 0.7$ \\
\hline
\end{tabular}

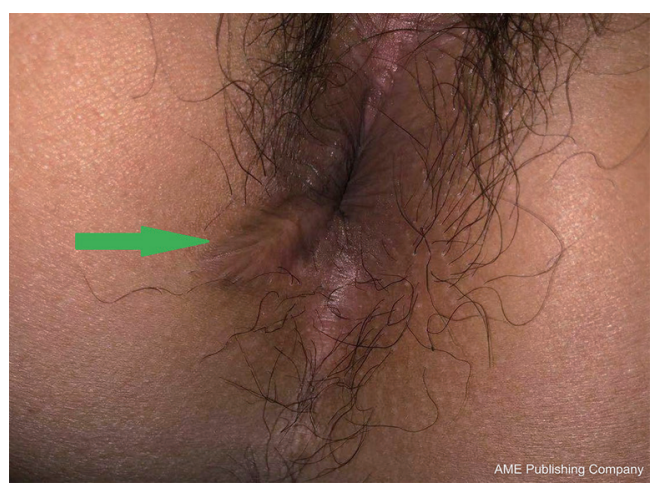

Figure 1 At approximately 4 years after surgery for high anal fistula, the perianal wound has recovered well, and local scars have formed (green arrow).

one $(4.5 \%)$ patient, while another patient $(4.5 \%)$ had two internal openings at 1 and 6 o'clock, respectively. In terms of shape, a semi-horseshoe was confirmed in 11 (50.0\%) patients, a full horseshoe was observed in six $(27.3 \%)$ patients, and a homotopic line was seen in three (13.6\%) patients. The patients' preoperative laboratory results are shown in Table 2. None of the patients had abnormal liver function, renal function, or other important results.

\section{Fistula bealing and recurrence}

All patients underwent LCCS successfully and safely. After the procedure, all patients were followed-up according to a scheduled timetable in our clinic. The follow-up visits included anal inspection, digital anal examination, endoanal ultrasonography, and anorectal manometry. The median follow-up time was 3.65 years (IQR: $3.55-$ 4.22; range, 3.50-5.43). The results of anal inspection revealed scarring clot in one $(4.5 \%)$ patient, and none of the patients showed malformation. Furthermore, no masses, induration, or tenderness were observed in any of the patients during digital anal examination. The 22 included patients underwent postoperative endoanal ultrasonography; all of them were found to have normal endoanal hypoechogenicity, and no gas or liquid shadow was observed. Endoanal ultrasonography revealed a soft scar in $16(72.7 \%)$ patients.

As shown in Table 2, 11 patients underwent postoperative anorectal manometry. The mean values of anal resting pressure, maximum systolic pressure, and rectal anal pressure difference were $76.9,139.8$, and $-62.9 \mathrm{mmHg}$, respectively. The mean length of the high-pressure zone was $4.0 \mathrm{~cm}$. Recto-anal inhibitory reflex was observed in 10 patients $(45.5 \%)$. Figures $1-3$ show a representation of typical cases.

\section{Incontinence}

According to the WCGS, 14 (63.6\%) patients did not present with any fecal incontinence at the follow-up visit (a Wexner score of 0 ), while eight patients reported a Wexner score of 1 . The median total Wexner score was 0 (range, 0-12). Compared to a previous study (19), two patients in the present study reported experiencing liquid incontinence "occasionally", three patients reported "occasionally" having flatus incontinence, two patients "occasionally" experienced solid stools, and one patient reported lifestyle alterations. No patients reported any further anal itching (Table 3).

\section{VAS score}

At the most recent postoperative follow-up visit, 21 (95.5\%) patients had a VAS score of 0 , and only one (4.5\%) patient had a VAS score of 1, which indicated that LCCS resulted in a long-term low risk of postoperative perianal pain.

\section{SF-36 questionnaire QOL assessment}

For each domain or specific item in the SF-36, all patients reported a final score of 100 , which indicates that the negative impact of HAF on patients' general health, physical activities, physical health, emotional health, social activities, and pain almost disappeared during the long-term followup after LCCS surgery.

\section{Discussion}

In the present study, we evaluated the results of long- 

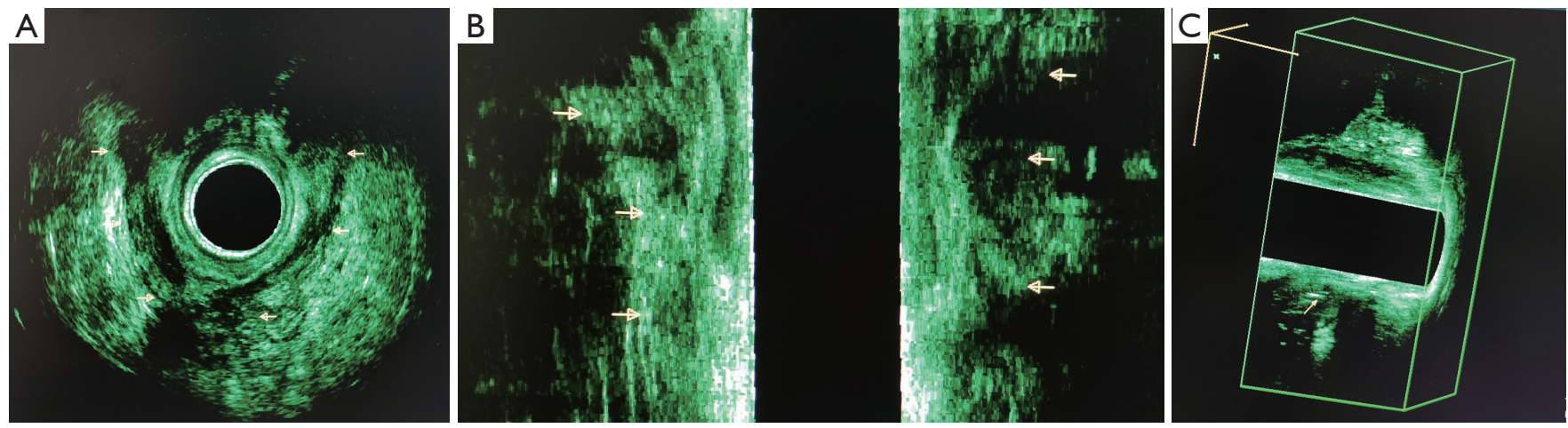

Figure 2 Preoperative ultrasound manifestation. (A) Thick and irregular low-echo zones (arrows) can be seen at the 1, 6, and 12 o'clock positions; (B) the proximal ends of both sides reach the level of the puborectalis muscle (arrows); (C) the 6 o'clock position of the inner mouth (arrows).
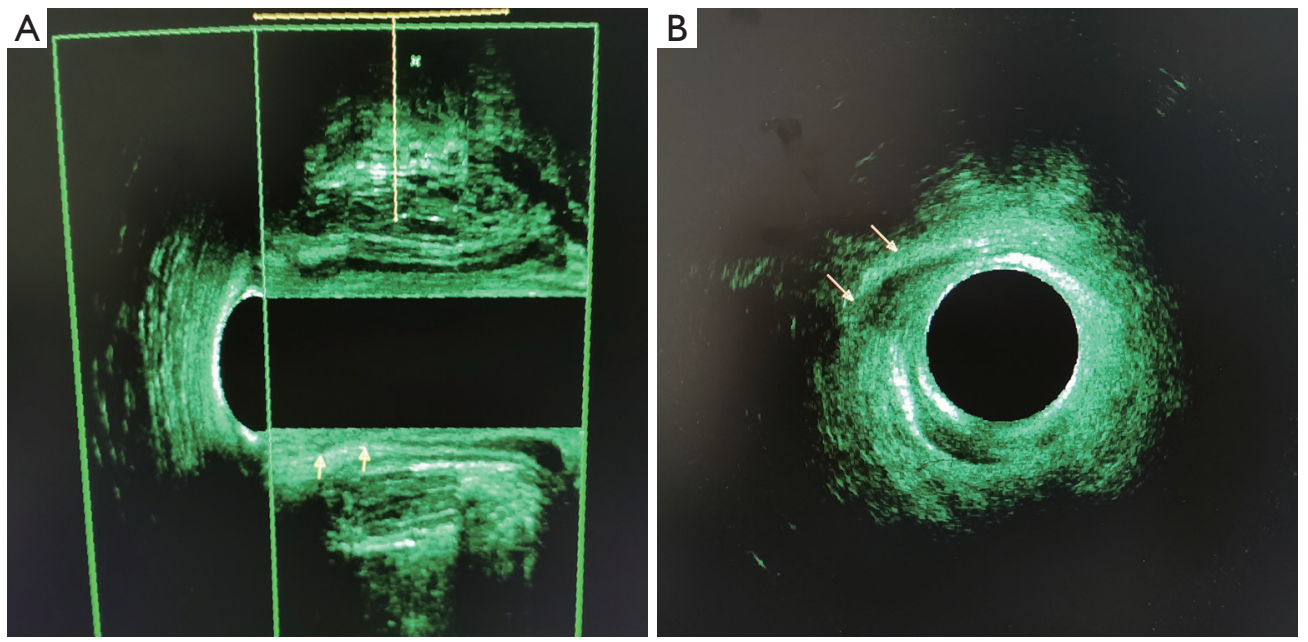

Figure 3 Postoperative ultrasound manifestation. (A) A defect in the middle and lower segment of the internal anal sphincter is visible (arrows) at the 6 o'clock position. (B) Scar, mixed echo, irregular edges (arrows).

term follow-up (average follow-up duration of 3.9 years) following LCCS for patients with HAF, which showed that LCCS has a favorable effect on these patients. During the 3.50-5.43 years after LCCS surgery, fistula was cured in all patients and none of the included patients reported fistula recurrence. In this period, the patients' QOL improved significantly compared with the preoperative status. As the first report of long-term follow-up after LCCS, our study supports LCCS as the primary choice for patients with HAF.

In the treatment of HAF, curing the lesion and simultaneously avoiding the surgery-related secondary damage to the sphincter presents a significant challenge for surgeons $(13,14,17)$. At present, few of the previously reported treatment strategies could entirely eliminate the
HAF while preserving patient's continence. Our previous retrospective study for the first time showed that LCCS could achieve a high cure rate with satisfying continence in most patients, as well as a low level of postoperative pain in the short-term (19). In the present study, we reported the long-term follow-up results to further demonstrate that LCCS is an effective, safe, and reliable method for the treatment of HAF.

LCCS has two effects: the first is the curative effectiveness of cutting seton (13) for drainage, and the second is anal protective effect offered by loose seton (20). In the present study, LCCS had a favorable effectiveness in the relatively short time needed for complete healing (mean healing duration of 40 days) with incomplete cutting of the 
Table 3 Postoperative Wexner continence grading scale scores of 22 patients with HAF

\begin{tabular}{|c|c|c|c|c|c|}
\hline Variables & Never & Rarely & Sometimes & Usually & Always \\
\hline Liquid, n (\%) & 20 (90.9) & $2(9.1)$ & $0(0.0)$ & $0(0.0)$ & $0(0.0)$ \\
\hline Flatus, n (\%) & $19(86.4)$ & $3(4.5)$ & $0(0.0)$ & $0(0.0)$ & $0(0.0)$ \\
\hline Wears pad, n (\%) & $22(10.0)$ & $0(0.0)$ & $0(0.0)$ & $0(0.0)$ & $0(0.0)$ \\
\hline
\end{tabular}

anorectal ring and the maintenance of continence, which is similar to the effects of loose seton after surgery, and also led to a long-term ( $>3$ years) beneficial efficacy without damage to the function of the sphincter.

In previous studies, investigators have attempted numerous methods in the treatment of HAF. Some methods were highly effective as they could simultaneously drain the abscess fluid, cut the fistula tract, and induce fibrosis along the channel, thereby leading to complete healing. In a study by Shira et al., the fistula was cured completely in $97.6 \%$ (363 cases) of the entire study cohort (372 cases); incontinence to flatus was reported from 58 patients $(15.6 \%)$, but none to feces. The fistula recurred in nine patients (2.4\%) (21). In a similar follow-up study, Patten et al. observed the long-term effect of cutting seton for HAF. The authors found that cutting seton had healing rates of $93 \%$ after the first operation and $98 \%$ after the second operation to treat recurrence of fistula. In total, $78 \%$ of patients had normal continence or non-specifically minor incontinence, $13.5 \%$ had moderate incontinence, and $8.5 \%$ had severe incontinence (18). Furthermore, in a randomized trial, Abdelnaby et al. compared the drained mucosal flap technique (group 1) with rerouting seton (group 2) around the internal anal sphincter (IAS) for treatment of HAF. Their results showed that one of the 49 patients in group 1 and two of the 48 patients in group 2 developed fecal incontinence, while failure to heal occurred in two patients in group 1 and four patients in group 2 (22). Compared with these studies, we achieved a $100 \%$ healing rate, $0 \%$ recurrence rate, and significant improvement of QOL in long-term follow-up.

As described in our previous article (19), the LCCS technique has several advantages. Briefly, compared to the rubber band, the cutting force of the silk thread is stronger and the cutting speed is more rapid, which results in a shorter operation time (30-120 minutes) (23). At the same time, silk thread cutting-induced pain during surgery is minimal. Moreover, damage to the anorectal ring caused by the silk thread is mild, thereby leading to a shorter recovery period and minimal scarring. Furthermore, the operation area needed for placing silk thread is very small, which might help to reduce the risk of secondary local or even systematic infection. This procedure does not totally cut apart the anorectal ring. In fact, in our clinical practice, we only cut apart a section of the anorectal ring during the surgery, with the complete cutting-off of the internal orifice of the fistula and dead tissue. Also, the silk seton is loosened on the $7^{\text {th }}$ day postoperatively. Therefore, LCCS preserves normal contraction and relaxation of the anal sphincter and reduce the risk of incontinence after surgery. Thirdly, no additional gauze dressing change is needed postoperatively. Infectious and dead tissue can be replaced by fresh granulation tissue along the drainage, which is enabled by the loosened silk thread, thereby healing the fistula. Therefore, pain experienced by patients can be reduced and the cost of gauze dressing changes is minimized.

This study has some limitations that should be noted. Firstly, the sample size in present study is relatively small. Secondly, this is a single center, observational study. Future research should enroll more patients across multiple medical centers to compare LCCS with other techniques in a randomized trial.

\section{Conclusions}

According to our present and previous studies, we believe that LCCS for HAF patients can achieve a high cure rate with a low risk of incontinence. It can also significantly improve the QOL of patients with HAF, as well as a reduced likelihood of postoperative pain. Therefore, randomized controlled trials are warranted to further confirm the longterm efficacy and safety of LCCS for patients with HAF. 


\section{Acknowledgments}

Funding: None.

\section{Footnote}

Reporting Checklist: The authors have completed the STROBE reporting checklist. Available at https://dx.doi. org/10.21037/atm-21-3242

Data Sharing Statement: Available at https://dx.doi. org/10.21037/atm-21-3242

Conflicts of Interest: All authors have completed the ICMJE uniform disclosure form (available at https://dx.doi. org/10.21037/atm-21-3242). The authors have no conflicts of interest to declare.

Ethical Statement: The authors are accountable for all aspects of the work in ensuring that questions related to the accuracy or integrity of any part of the work are appropriately investigated and resolved. This study was conducted in accordance with the principles of the Declaration of Helsinki (as revised in 2013), and was approved by the ethics committee of the China-Japan Friendship Hospital (approval license No.: 2019-SFZX-7). Written informed consent was obtained from every patient who was eventually enrolled in this study.

Open Access Statement: This is an Open Access article distributed in accordance with the Creative Commons Attribution-NonCommercial-NoDerivs 4.0 International License (CC BY-NC-ND 4.0), which permits the noncommercial replication and distribution of the article with the strict proviso that no changes or edits are made and the original work is properly cited (including links to both the formal publication through the relevant DOI and the license). See: https://creativecommons.org/licenses/by-nc-nd/4.0/.

\section{References}

1. Zanotti C, Martinez-Puente C, Pascual I, et al. An assessment of the incidence of fistula-in-ano in four countries of the European Union. Int J Colorectal Dis 2007;22:1459-62.

2. Ommer A, Herold A, Berg E, et al. German S3 guidelines: anal abscess and fistula (second revised version). Langenbecks Arch Surg 2017;402:191-201.
3. Zhang Y, Li F, Zhao T, et al. Efficacy of video-assisted anal fistula treatment combined with closure of the internal opening using a stapler for Parks II anal fistula. Ann Transl Med 2020;8:1517.

4. Abdullaev Z, Agzamkhodjaev S, Chung JM, et al. Risk factors for fistula recurrence after urethrocutaneous fistulectomy in children with hypospadias. Turk J Urol 2021;47:237-41.

5. Chaveli Díaz C, Esquiroz Lizaur I, Eguaras Córdoba I, et al. Recurrence and incidence of fistula after urgent drainage of an anal abscess. Long-term results. Cir Esp (Engl Ed) 2020. [Epub ahead of print]. doi: 10.1016/ j.ciresp.2020.11.010.

6. He C, Chen Z, Liu S, et al. Prevalence and risk factors of interstitial lung disease in patients with primary Sjogren's syndrome: A systematic review and meta-analysis. Int J Rheum Dis 2020;23:1009-18.

7. Cheung FY, Appleton ND, Rout S, et al. Videoassisted anal fistula treatment: a high volume unit initial experience. Ann R Coll Surg Engl 2018;100:37-41.

8. Handaya AY, Fauzi AR. Combined Fistulotomy and Contralateral Anal Internal Sphincterotomy for Recurrent and Complex Anal Fistula to Prevent Recurrence. Ann Coloproctol 2020;36:122-7.

9. Jiang J, Zhang Y, Ding X, et al. Efficacy and safety of an innovatively modified cutting seton technique for the treatment of high anal fistula: A protocol for a randomized controlled trial. Medicine (Baltimore) 2021;100:e24442.

10. Emile SH, Khan SM, Adejumo A, et al. Ligation of intersphincteric fistula tract (LIFT) in treatment of anal fistula: An updated systematic review, meta-analysis, and meta-regression of the predictors of failure. Surgery 2020;167:484-92.

11. Zwiep TM, Gilbert R, Boushey RP, et al. Comparison of Ligation of the Intersphincteric Fistula Tract and BioLIFT for the Treatment of Transsphincteric Anal Fistula: A Retrospective Analysis. Dis Colon Rectum 2020;63:365-70.

12. Bakhtawar N, Usman M. Factors Increasing the Risk of Recurrence in Fistula-in-ano. Cureus 2019;11:e4200.

13. Subhas G, Singh Bhullar J, Al-Omari A, et al. Setons in the treatment of anal fistula: review of variations in materials and techniques. Dig Surg 2012;29:292-300.

14. Mitalas LE, van Wijk JJ, Gosselink MP, et al. Seton drainage prior to transanal advancement flap repair: useful or not? Int J Colorectal Dis 2010;25:1499-502.

15. Choi D, Sung Kim H, Seo HI, et al. Patient-performed seton irrigation for the treatment of deep horseshoe fistula. 
Dis Colon Rectum 2010;53:812-6.

16. Emile SH, Elfeki H, Thabet W, et al. Predictive factors for recurrence of high transsphincteric anal fistula after placement of seton. J Surg Res 2017;213:261-8.

17. Yan J, Ma L. Clinical Effect of Tunnel-Like Fistulectomy Plus Draining Seton Combined with Incision of Internal Opening of Anal Fistula (TFSIA) in the Treatment of High Trans-Sphincteric Anal Fistula. Med Sci Monit 2020;26:e918228.

18. Patton V, Chen CM, Lubowski D. Long-term results of the cutting seton for high anal fistula. ANZ J Surg 2015;85:720-7.

19. Zheng L, Shi Y, Zhi C, et al. Loose combined cutting seton for patients with high intersphincteric fistula: a retrospective study. Ann Transl Med 2020;8:1236.

20. Kelly ME, Heneghan HM, McDermott FD, et al. The role of loose seton in the management of anal fistula: a multicenter study of 200 patients. Tech Coloproctol 2014;18:915-9.

21. Shirah BH, Shirah HA. The Impact of the Outcome of Treating a High Anal Fistula by Using a Cutting Seton and Staged Fistulotomy on Saudi Arabian Patients. Ann Coloproctol 2018;34:234-40.

22. Abdelnaby M, Emile S, El-Said M, et al. Drained mucosal advancement flap versus rerouting Seton around the internal anal sphincter in treatment of high transsphincteric anal fistula: A randomized trial. Int J Surg 2019;72:198-203.

23. Hanley PH. Rubber band seton in the management of abscess-anal fistula. Ann Surg 1978;187:435-7.

(English Language Editor: A. Kassem)

Cite this article as: Zhi C, Huang Z, Liu D, Zheng L. Long-term follow-up study of loose combined cutting seton surgery for patients with high anal fistula. Ann Transl Med 2021;9(14):1160. doi: 10.21037/atm-21-3242 